\title{
Factors Affecting Farmer's Chemical Fertilizers Consumption and Water Pollution in Northeastern Iran
}

\author{
Hosein Mohammadi ${ }^{1}$, Abdolhamid Moarefi Mohammadi ${ }^{2} \&$ Solmaz Nojavan $^{1}$ \\ ${ }^{1}$ Agricultural Economics Department, Agriculture Faculty, Ferdowsi University of Mashhad, Iran \\ ${ }^{2}$ Department of Economics, University of Isfahan, Isfahan, Iran \\ Correspondence: Hosein Mohammadi, Agricultural Economics Department, Agriculture Faculty, Ferdowsi \\ University of Mashhad, Iran. Tel: 98-915-102-5098. E-mail: hoseinmohammadi@um.ac.ir
}

Received: November 25, 2016

Accepted: December 22, 2016

Online Published: January 15, 2017

doi:10.5539/jas.v9n2p234

URL: http://dx.doi.org/10.5539/jas.v9n2p234

\begin{abstract}
Pollution by fertilizers containing nitrogen is one of the most significant sources of water pollution, and agriculture sector has a considerable share in this type of pollution. In this study, factors affecting the level of contamination of surface and underground water resources by agricultural activities were examined. Data of 254 wheat farmers in the plain of Mashhad in Khorasan Razavi province in Iran were used for investigating the effect of some explanatory variables on the level of water pollution utilizing Ordered Logit Regression Model. The results show that main activity of farmers, years of experience, the level of education, awareness of organic farming, level of income, price of fertilizers and irrigation method have significant effect on the amount of fertilizers utilized by farmers and hence the level of water resources pollution. Efforts for decreasing pollution of water resources require strategies such as changing the main activity of farmers, increase the cost of using chemical fertilizers, create economic incentives for organic farming, and increase general information and knowledge of farmers.
\end{abstract}

Keywords: agriculture, chemical fertilizers, environment, nitrogen, ordered logit regression, water pollution

\section{Introduction}

Population growth and increasing water demand in various sectors of agriculture, industry and drinking water, has caused great pressure on groundwater resources. More than one billion people in the world have limited access to safe water and the major source of $80 \%$ of water in developing countries is from poor quality and unhealthy water resources. Usually in developing countries, the priority is finding suitable and clean underground aquifers to supply water for drinking and agricultural activities, while in developed countries; more attention is drawn to the issue of water quality (Seldon \& Song, 1994).

Agricultural activities might have negative impacts on the environment. Water pollution from agriculture is defined as non-point source of pollution. Actors involved are many and it is quite a complex matter to define how and when polluting agent enters the water bodies and who the polluters are (Semaan et al., 2007). In the last decades, concerns about groundwater pollution caused by excessive utilization of nitrogen fertilizers in agricultural areas have increased (de Paz \& Ramos, 2004). Nutrient pollution is one of the most widespread, costly and challenging environmental problems, and is caused by excess nitrogen and phosphorus in the air and water. When too much nitrogen and phosphorus enters the environment, usually from a wide range of human activities, the air and water can be polluted (EPA, 2016). Collins et al. (2016) emphasize that controlling excessive emissions of pollutants into water and air is a major policy challenge in several countries.

Majority of fertilizers contain nitrogen $(\mathrm{N})$ because nitrogen is an essential nutrient for the growth of plants and its deficiency in the soil can affect the growth of plants. Nevertheless, if these fertilizers are not properly use, $\mathrm{N}$ can enter through rainfall or irrigation into surface and groundwater resources and it can contaminate water resources. To maximize production and minimize the environmental damages resulting from the use of $\mathrm{N}$, studying the factors affecting consumption of these fertilizers is necessary. Excess amount of nitrogen in ground and surface waters is a serious problem in intensive agriculture areas, largely due to poor efficiency in using $\mathrm{N}$ and this subject has several reasons, including not timing $\mathrm{N}$ application to crop requirements and excess $\mathrm{N}$ application. Chemical fertilizers producing industries that provide the nitrogen needed to grow plants in the form 
of ammonium $\left(\mathrm{NH}_{4}{ }^{+}\right)$or nitrate $\left(\mathrm{NO}_{3}{ }^{-}\right)$are the main sources that produce nitrogen pollutants. Another form of $\mathrm{N}$ is found in urea fertilizers which when used in the soil, is rapidly converted to ammonium by natural enzymes. Compound fertilizers containing $\mathrm{N}$ such as ammonium, nitrate and urea are known as quick-release fertilizers because in these fertilizers, $\mathrm{N}$ dissolves rapidly in water to be utilized for plants. Excess nitrogen in the environment can contributes to many health and environmental problems such as coastal dead zones and fish kills, groundwater pollution, reduced crop productivity and global climate change (UNEP, 2014). Because the rapid dissolution of $\mathrm{N}$ can lead to environmental problems, the use of $\mathrm{N}$ fertilizers should be at standard levels.

Some companies produce and market slow release or controlled released fertilizers that released $\mathrm{N}$ with delays. Nevertheless, $\mathrm{N}$ fertilizers with quick or controlled rate of dissolution can be equally harmful to the environment if not properly utilized (Shober, 2014).

Emission of nitrogen into water resources has been a continuous process in different parts of the world including Europe, despite different regulations that have been enacted. Part of this problem is as a result of lack of enforcement and implementation of laws and the main part of the problem is due to excessive pollutants entering the environment. In these regards, the agriculture sector has a significant contribution in reducing the quality of water resources and about $55 \%$ of the nitrogen entering into water resources in the Europe is due to activities of the agricultural sector (Bouraoui \& Grizzetti, 2013).

Agriculture is the single largest user of freshwater resources, using a global average of $70 \%$ of all surface water supplies. Agriculture is both cause and victim of water pollution. It is a cause via its discharge of pollutants and it is a victim via the use of wastewater and polluted surface and groundwater, which contaminate crops and transmit disease to consumers and farm workers (FAO, 1996).

Groundwater resources are mainly polluted by nitrates. In several areas, the groundwater is polluted to an extent that it is no longer fit to be used as drinking water according to present standards. Agriculture also makes a substantial contribution to the total atmospheric nitrogen loading into the North and the Baltic Seas. This amounts to 65 and 55\% respectively (FAO, 1996).

Due to increase in world population and change in eating habits, it is anticipated that until 2020, consumption of nitrogen and phosphorus fertilizers will reach up to $114 \times 10^{6} t N$ and $21 \times 10^{6} t P$ respectively (Bumb \& Baanate, 1996).

Peña-Haro et al. (2010) by utilizing the hydro-economic modeling framework, consider the relationship between fertilizer application and concentration of nitration on the ground water resources at different control sites while maximizing net economic benefits. Their results demonstrate that a high fertilizer price would be needed to decrease nitrate concentrations in groundwater below the standard of $50 \mathrm{mg} / \mathrm{l}$.

Between 1983 and 2005, the average usage of chemical fertilizers per hectare has increased from 169 to $390 \mathrm{~kg}$ and Two-thirds of these fertilizers are nitrogen-containing fertilizers. In this period, average cereal production has increased from 3.7 to 5.3 tons per hectare. The results of other studies had demonstrated a high positive correlation between annual production of food products and consumption of fertilizers in recent years (Zhu \& Chen, 2002). Increasing use of fertilizers containing nitrogen imposed various costs on the society. In most fertile land, the rate at which nitrogenous fertilizers are consumed is very high and it not only increases production costs and decreases efficiency, but also has various negative impacts on air and water quality (Zhou et al., 2010).

In many fertile areas of Iran, annual consumption of nitrogen base fertilizers are more than $350 \mathrm{~kg}$ per hectare which is much more than standard levels (Mahvi et al., 2005). Khamadi et al. (2015) showed that increasing application of $\mathrm{N}$ fertilizers in wheat farms from 160 to $360 \mathrm{~kg}$ per hectare, would decrease the efficiency of nitrogen fertilizers in Iran. According to Wang et al. (2004) excessive application of $\mathrm{N}$ fertilizer for wheat production has resulted in environment pollution. These researchers found that the optimal $\mathrm{N}$ application rate is $180-225 \mathrm{~kg} \mathrm{~N} \mathrm{hm}^{-2}$ for wheat which resulted in the highest yield with standard pollution. Sharasbi et al. (2016) showed that in Iran conditions, the maximum grain yield and biological yield were obtained in 150 and $225 \mathrm{~kg} \mathrm{~N}$ $\mathrm{hm}^{-2}$ under normal irrigation condition. Nevertheless, nitrogen application up to optimum level enhanced grain yield, yield components and water productivity, but as water stress intensified, the positive effect of nitrogen fertilizer was diminishes. Seyed Sharifi et al. (2016) also showed that in Iran, the maximum yield, yield components, rate and grain filling period for wheat belonged to application of $180 \mathrm{~kg} \mathrm{~N} \mathrm{hm}^{-2}$.

It seems that several factors affect the amount of nitrogen fertilizers used by farmers such that by identifying the most important and influential factors, we can offer suggestions for reducing nitrogen fertilizers application and hence reduce water resources pollution. 
This study attempts to identify the factors influencing the consumption of nitrogen-containing fertilizers by farmers in the plains of Mashhad. These factors are those other than soil type, terrain, weather and factors that are beyond human controls and can affect the amount of nitrogen absorption on water resources. These factors include; main activity of farmers, farming experience, farmers education, farmers income, price of fertilizer, irrigation method, fertilizing method, awareness of organic farming and awareness of the dangers of water pollution. Mashhad, which is the top city in Khorasan Razavi province, has about 90,000 hectares of cultivation areas and around $55 \%$ of them are irrigated by water and $45 \%$ are rain-fed cultivation. Around $66 \%$ of cereal cultivation in Mashhad Plain is devoted to irrigated wheat (Ansari et al., 2014).

The $\mathrm{N}$ requirement depends on many factors such as soil type and the cultivars, the climate conditions, crop type and other conditions that they are beyond the objective of this research. Therefore, by selecting Mashhad plains that have similar conditions for soil and temperature and by selecting only single product, our objective was to investigate the effect of human factors on the use of nitrogen base fertilizers and therefore water pollution.

\section{Methods}

To analyze the factors affecting the level of water resources pollution caused by the amount of chemical fertilizers consumed by farmers, Ordered Logit Model was employed. OLM is based on latent variable and in this study; it is the real amount of water pollution caused by the consumption of chemical fertilizers. latent variable is defined as follows:

$$
y_{i}^{*}=X_{i} \beta+\varepsilon_{i} \quad-\infty<y_{i}^{*}+\infty
$$

Where, $y_{i}{ }^{*}$ is continuous variable that shows the real amount of water pollution by nitrogenous fertilizers. $\beta$ is a vector of parameters that should be estimated. $X_{i}$ is a vector of explanatory variables and $\varepsilon_{i}$ is error term that has logestic distribution. Since $y_{i}^{*}$ is not observable, the standard regression technique such as Ordinary Least Square (OLS) is not applicable (Long, 1997).

If $y_{i}$ be discrete and observable variable that exhibits the level of pollution, the relationship between unobservable variable $y_{i}{ }^{*}$ and $y_{i}$ can be obtain by ordered logit model as follows:

$$
\begin{array}{lll}
y_{i}=1 & \text { if }-\infty \leq y_{i}^{*}<\tau_{1} & i=1, \ldots, n \\
y_{i}=2 & \text { if } \tau_{1} \leq y_{i}^{*}<\tau_{2} & i=1, \ldots, n \\
y_{i}=3 & \text { if } \tau_{2} \leq y_{i}^{*}<\tau_{3} & i=1, \ldots, n \\
y_{i}=4 & \text { if } \tau_{3} \leq y_{i}^{*}<\tau_{4} & i=1, \ldots, n
\end{array}
$$

In these relationships, $\mathrm{n}$ is sample size and $\tau^{\prime} \mathrm{s}$ are thresholds that define observable discrete responses and should be estimated. The probability that $y_{i}=J$ can be calculated as Equation (3):

$$
\operatorname{Pr}\left(y_{i}=J\right)=\operatorname{Pr}\left(\varepsilon_{i}<\tau_{J}-X_{i} \beta \mid X_{i}\right)-\operatorname{Pr}\left(\varepsilon_{i}<\tau_{J-1}-X_{i} \beta \mid X_{i}\right)=F\left(\tau_{J}-X_{i} \beta \mid X_{i}\right)-F\left(\tau_{J-1}-X_{i} \beta \mid X_{i}\right)
$$

In this equation, $F$ is cumulative distribution function (CDF) for $\varepsilon$ and $\beta$ is a column vector of parameters and $X_{i}$ is a vector of independent variables. One important test in OLM is the assumption of parallel regression. In this test, we assume equal $\beta$ for each level of dependent variable. Parallel regression test (Brant and Likelihood ratio), assesses the rightness of parameters equality for all groups of dependent variable. Null hypothesis in this test is that $\beta$ is the same for all groups.

Model Equation (3) can be estimated by using Maximum Likelihood (ML) method and marginal effects of each variable usually calculated in the means of other variables and summation of marginal effects for each variable is zero. The marginal change in the probability can be computed as follows:

$$
\frac{\partial \operatorname{Pr}(y=m \mid X)}{\partial x_{k}}=\frac{\partial F\left(\tau_{m}-X \beta\right)}{\partial x_{k}}-\frac{\partial F\left(\tau_{m-1}-X \beta\right)}{\partial x_{k}}
$$

Which is the slope of the curve relating $x_{k}$ to $\operatorname{Pr}(\mathrm{y}=\mathrm{m} \mid \mathrm{X})$, holding all other variables constant (Long, 1997).

As previously mentioned, the aim of this study is to evaluate factors affecting water pollution by agricultural activities. To achieve this goal, we apply the OLM and our research model is as follows:

$$
Y_{i}=\alpha_{0}+\beta_{1} a c t+\beta_{2} \exp +\beta_{3} s a t+\beta_{4} e d u+\beta_{5} a w a+\beta_{6} \text { org }+\beta_{7} w a y+\beta_{8} i n c+\beta_{9} w a t+\beta_{10} p r i c e+\varepsilon_{i}
$$

In Equation (5), $Y_{i}$ is dependent variable that shows the level of pollution entering into water resources by farmer $i$. This variable is divided into three categories and its description is shown in Table 1.

Classification of dependent variable is based on the level of chemical fertilizers containing nitrogen used by farmers during planting periods. We have three categories for dependent variables. In the first category, farmers 
use less than $180 \mathrm{~kg} \mathrm{~N} \mathrm{hm}^{-2}$, in the second category, farmers use standard level (between 180-225 $\mathrm{kg}^{\text {) of N hm}} \mathrm{h}^{-2}$ while in the third category, farmers use more than $225 \mathrm{~kg} \mathrm{~N} \mathrm{hm}^{-2}$ in planting season.

Data and information for this study were collected by completing questionnaires from 254 wheat farmers in the plains of Mashhad. Simple random sampling method was used for selecting a random sample of farmers in this area. About one million hectare of lands in Khorasan Razavi province are cultivated by irrigated and rain-fed crops and this area is the third regarding the area under cultivation in Iran.

\section{Results}

Descriptive statistics of data are reported in Tables 1 and 2. In Table 1, the frequency of each category of dependent variable reported. Due to the use of nitrogen fertilizers, pollution of water resources by farmers is classified into three groups of; low pollution (1), medium (standard) pollution (2) and high pollution (3).

Table 1. Level and frequency of dependent variable

\begin{tabular}{llll}
\hline Level of Dependent Variable & Frequency & Percentage Frequency & Cumulative Frequency \\
\hline 1 & 30 & 11.8 & 11.8 \\
2 & 89 & 35 & 46.8 \\
3 & 135 & 53.2 & 100 \\
Total & 254 & 100 & \\
\hline
\end{tabular}

Table 2 shows the descriptive statistics of all variables.

Table 2. Descriptive statistics of variables

\begin{tabular}{llllll}
\hline Variable & Mean & Standard Error & Min & Max & Description \\
\hline Pollution & 2.2 & 0.45 & 1 & 3 & Level of pollution by nitrogen fertilizers \\
Main Activity & 0.52 & 0.502 & 0 & 1 & Agriculture $=1$ and Other $=0$ \\
Experience & 29.14 & 7.5 & 8 & 60 & Farmers experience in year \\
Cultivation levels & 1.52 & 1.04 & 0.3 & 4 & Levels of cultivation in terms of hectare \\
Education & 7 & 4 & 0 & 15 & Farmers education in years \\
Awareness of Pollution damages & 0.44 & 0.28 & 0 & 1 & Aware $=1$ and Not aware $=0$ \\
Awareness of Organic farming & 0.47 & 0.37 & 0 & 1 & Aware $=1$ and Not aware $=0$ \\
Fertilizing Method & 0.31 & 0.26 & 0 & 1 & By hand $=0$ and by machine $=1$ \\
Income & 13 & 5.6 & 3.5 & 45 & Annual farmers income \\
Fertilizers Price & 0.57 & 0.23 & 0 & 1 & Low $=0$ and High $=1$ \\
Irrigation method & 0.48 & 0.33 & 0 & 1 & Drop $=0$ and submerge $=1$ \\
\hline
\end{tabular}

The results of the ordered logit regression model are reported in Table 3. The results show that main activity of farmers, years of experience, the level of education, awareness of organic farming, level of income, price of fertilizers and irrigation method have significant effect on the amount of nitrogen entering into the water resources and therefore water pollution. Main activity, experience, level of income and irrigation method have direct and positive effect on water pollution; on the other hand, education, awareness of organic farming and price of fertilizers have indirect and negative effect on water resource pollution. 
Table 3. Ordered logit regression model results

\begin{tabular}{|c|c|c|c|c|}
\hline Variable & Coefficient & Standard Deviation & Z statistic & Prob. \\
\hline Main Activity & $0.82 *$ & 0.43 & 1.91 & 0.06 \\
\hline Experience & $0.068 * *$ & 0.031 & 2.18 & 0.031 \\
\hline Cultivation levels & 0.25 & 0.19 & 1.3 & 0.19 \\
\hline Education & $-0.53 *$ & 0.31 & -1.7 & 0.09 \\
\hline Awareness of Pollution & 0.26 & 0.48 & 0.58 & 0.55 \\
\hline Awareness of Organic & $-0.97 *$ & 0.55 & 1.76 & 0.08 \\
\hline Fertilizing Method & 0.01 & 0.5 & 0.02 & 0.98 \\
\hline Income & $0.28 * *$ & 0.14 & 2.02 & 0.04 \\
\hline Price & $-0.46^{*}$ & 0.25 & 1.84 & 0.06 \\
\hline Irrigation method & $0.81^{*}$ & 0.47 & 1.72 & 0.08 \\
\hline$\tau_{1}$ & $4.85^{* *}$ & 2.62 & 1.85 & 0.06 \\
\hline$\tau_{2}$ & $4.21^{*}$ & 1.88 & 2.24 & 0.04 \\
\hline Log likelihood $=-97.57$ & & LRchi2 $(10)=21.28$ & & \\
\hline$R_{M c F}=0.298$ & & Prob $>$ chi $2=0.011$ & & \\
\hline
\end{tabular}

The Likelihood Ratio (LR) chi-square test compares a given model to the constraint model in which all slope coefficients are equal to zero. As shown by the results, we can reject the hypothesis that all coefficients except the intercept are zero.

Since the main activity has positive and significant effect on the level of dependent variable, farmers that take agriculture as their main occupation are more likely to cause pollution of water resources. Farmers who don't have any other occupation other than agriculture depend on this main activity for their lives and livelihoods. They try to earn more money from this core business and therefore with excessive use of chemical fertilizers, in an effort to increase their incomes, unleash more pollution into water resources. Thus, efforts to reduce water pollution should include policies that change farmer's main activity to other activities that do not impose high social costs such as environmental pollution to the community.

Farmers experience also has positive and significant effect on the level of dependent variable. In other words, farmers with more experience in agriculture, find that with extra usage of chemical fertilizers, they can achieve higher production and income levels with no expenses which are detrimental to the environment as well. On the other hand, the prices of fertilizer have negative and significant effect on the level of dependent variable. Thus increasing the price of fertilizers can diminish the amount of fertilizers used by farmers. Hence raising the cost of utilizing chemical fertilizers containing nitrogen with economic tools, can reduce the consumption of these fertilizers and reduce environmental damage.

Education has negative effect on the probability of increasing pollution of water resources. Farmers that have greater education utilize lower level of fertilizers, and hence unleash less pollution on water resources. Farmers with more education utilized more environmental friendly and scientific solutions for increasing production and reducing their costs in farming. Moreover, educated farmers mainly know the exact time for using chemical fertilizers to achieve maximum productivity (Noshad, 2014). Therefore, employing educated farmers in agricultural activities can have a significant impact on the reduction of pollution.

Awareness of farmers about organic farming is another variable that has negative impact on the level of water pollution. When farmers are aware of the benefits and techniques of organic farming, they will use less chemical fertilizers and pesticides and hence the chance of water resources pollution is reduced. This result is consistent with other studies in this field. For instance, Pitmentel et al. (2011) stated that organic practices lead to increased water retention and using organic methods and materials can allow for a slower release of chemicals into water resources. Agricultural organic products due to their superior quality could be a good candidate for nonorganic products and by improving the general health of the society, can reduce the contamination of water and soil pollution. Efforts to increase awareness of organic farming and its benefits as well as creating rational economic returns could reduce water resources pollution.

Farmer's income has a positive and significant effect on the level of water pollution because when farmer's income increases, they could buy more fertilizers and pesticides and even use more water in their farms, thereby 
increasing water resources pollution. Using economic instruments for reducing the use of chemical fertilizers can control the level of pollution to the standard levels.

Finally, irrigation method has significant effect on the level of water resources pollution and farmers that apply submerge method for irrigating their farms are more likely to cause more pollution to water sources. According to FAO (2011), poor irrigation has one of the worst impacts on water quality, whereas precision irrigation is one of the least polluting practices as well as decreasing the net cost of supplied water. Developing sprinkler and drip irrigation methods can decrease the possibility of contamination of water resources.

Table 4 presents the results of ordered logit regression model in terms of marginal effects. It should be noted that variables such as main activity, awareness of organic farming, price of fertilizers and irrigation method, are discrete and dichotomous variables and when these variables change (with all other variables held at their mean constant), the possibility that the dependent variable stand in each of the three levels, will change as indicated in Table 4.

Table 4. Marginal effects of ordered logit model

\begin{tabular}{llll}
\hline Marginal effect of Dependent Variable & $\begin{array}{l}\text { Group 1 } \\
\text { (Low Pollution) }\end{array}$ & $\begin{array}{l}\text { Group 2 } \\
\text { (Medium Pollution) }\end{array}$ & $\begin{array}{l}\text { Group 3 } \\
\text { (High Pollution) }\end{array}$ \\
\hline Main Activity* & -0.1887 & 0.0516 & 0.1371 \\
Experience* & -0.0157 & 0.0042 & 0.0115 \\
Cultivation levels & -0.058 & 0.047 & 0.011 \\
Education* & 0.122 & -0.033 & -0.089 \\
Awareness of Pollution & -0.062 & 0.018 & 0.044 \\
Awareness of Organic* & 0.21 & -0.03 & -0.18 \\
Fertilizing Method & -0.002 & 0.0006 & 0.0014 \\
Income* & -0.0667 & 0.0181 & 0.0486 \\
Price* & 0.121 & -0.037 & -0.084 \\
Irrigation method* & -0.189 & 0.052 & 0.137 \\
\hline
\end{tabular}

For instance, the results in Table 4 indicates that when the main activity of farmers is agriculture, the possibility that farmers stand on group 1 with low pollution reduces by $0.19 \%$ and the possibility that they stand on group 2 with medium pollution and in the group 3 with high pollution increase by 0.05 and $0.14 \%$ respectively. Again, the results of Table 3 are repeated in Table 4 in terms of marginal effects and for three level of dependent variable.

For other continuous variables such as experience, education and income, it says that when these variables change by one percent, the possibility that dependent variable lies in each group of dependent variable, changes by the percent reported in Table 4. For example, when the income of farmers increases by one percent, the possibility that they stand in group 1 with low level of pollution reduces by $0.066 \%$ and the possibility that farmers stand on group 2 with medium pollution or stand on group 3 with high pollution, increases by 0.018 and $0.048 \%$ respectively.

Table 5 presents the results of parallel regression test in ordered logit model. One of the assumptions in the ordered logit model is that for any independent variable, the coefficient of parameters $\left(\beta_{s}\right)$ in all groups of dependent variable are the same. Hence, the null hypothesis in the parallel regression test is that for all groups of dependent variable, parameters are identical (Long, 1997).

Table 5. The results of parallel regression test

\begin{tabular}{llll}
\hline Test & Chi-square & df & Prob. \\
\hline Brant & 8.32 & 9 & 0.502 \\
LR & 9.08 & 9 & 0.42 \\
WALD & 7.89 & 9 & 0.54 \\
\hline
\end{tabular}


The results in Table 5 indicate that the null hypothesis is not rejected and so the ordered logit model is accepted and it can show the relationships between explanatory variables and the groups of dependent variable as well. If $H_{0}$ is rejected, we can use other methods such as generalized ordered logit models.

\section{Discussion}

In this study, factors affecting the level of consumption of fertilizers by farmers, and thus absorption of nitrogen in water resources were investigated in Mashhad plain area. The results from ordered logit model show that explanatory variables such as main activity, farmers experience, farmers education, awareness of organic farming, income, price of fertilizers and irrigation methods have significant effect on the level of dependent variable.

Efforts to reduce water pollution should include policies that change farmer's main activity to other activities such as complementary jobs in agricultural sector that do not impose high social costs to the community. Furthermore, increasing the price of fertilizers to an optimal level can reduce the amount of fertilizers utilized by farmers, thereby reducing environmental pollution.

Developing formal and informal educational centers for farmers and employing educated farmers in agricultural activities can have a significant effect on the reduction of pollution and when farmers are aware of the benefits and techniques of organic farming, they will use less chemical fertilizers and pesticides, thereby reducing the contamination of water resources. Efforts to increase awareness about organic farming as well as government support from these groups of farmers and finally creating rational economic returns could reduce the pollution of water resources. Developing sprinkler and drip irrigation methods also can decrease the possibility of contaminating water resources.

Finally, it is proper to mention that the solutions proffered in this study for reducing water pollution will be more effective when they are carried out simultaneously and together. For example, by raising the cost of chemical fertilizers, rational economic incentives for organic farming are create and the general knowledge and education of farmers increase. Secondly, the solutions should fit into the overall culture and the level of development of a region or a country. Strategies mentioned in this article are mainly for developing countries like Iran, where their main priority is earning more income from agricultural activities rather than considering environmental issues. Therefore, the results of other similar studies especially in developed countries may somewhat vary with the results of the present study.

\section{References}

Ansari, H., Salarian, M., Takarli, A., \& Bayram, M. (2014). Determining Optimum Irrigation Depth for Wheat and Tomato Crops Using Aqua crop Model (A Case study in Mashhad). Iranian Journal of Irrigation and Drainage, 8, 86-95.

Bouraoui, F., \& Grizzetti, B. (2013). Modeling mitigation options to reduce diffuse nitrogen water pollution from agriculture. Science Total Environment, 15, 468-469. https://doi.org/10.1016/j.scitotenv.2013. 07.0662013

Bumb, B. L., \& Baanate, C. A. (1996). World Trends in Fertilizer Use and Projections to 2020. International Food Policy Research Institute. Washington DC. Retrieved from http://www.ifpri.org/2020/briefs/ number38.htm

Collins, A. L., Zhang, Y. S., Winter, M., Inman, A., Jones, J. I., Johnes, P. J., ... Noble, L. (2016). Tackling agricultural diffuse pollution: What might uptake of Farmer-preferred measures deliver for emissions to water and air? Science of the Total Environment, 547, 269-281. https://doi.org/10.1016/j.scitotenv.2015. 12.130

De Paz, J. M., \& Ramos, C. (2004). Simulation of nitrate leaching for different nitrogen fertilization rates in a region of Valencia (Spain) using a GIS-GLEAMS system. Agriculture, Ecosystems and Environment, 103, 59-73. https://doi.org/10.1016/j.agee.2003.10.006

Khamadi, F., Mesgarbashi, M., Hosaibi, P., Enaiat, N., \& Farzaneh, M. (2015). The effect of crop residue and nitrogen fertilizer levels on soil biological properties and nitrogen indices and redistribution of dry matter in wheat. Agronomy Journal, 28(4), 149-157.

Long, S. J. (1997). Regression Models for Categorical and Limited Dependent Variables. SAGE Publication, London.

Mahvi, A. H., Nouri, J., Babaei, A. A., \& Nabizadeh, R. (2005). Agricultural activities impact on groundwater nitrate pollution. Int. J. Environ. Sci. Tech., 2, 41-47. https://doi.org/10.1007/BF03325856 
Noshad, H. (2014). The amount and timing of nitrogen application in sugar beet cultivation. Organization of Research, Education and Promoting of Agriculture, Iran.

Ongley, E. D. (1996). Control of water pollution from agriculture, GEMS/Water Collaborating Centre, Canada Centre for Inland Waters. Food and Agriculture Organization of the United Nations, Rome.

Peña-Haro, S., Llopis-Albert, C., Pulido-Velazquez, M., \& Pulido-Velazquez, D. (2010). Fertilizer standards for controlling groundwater nitrate pollution from agriculture: ElSalobral-Los Llanos case study, Spain. Journal of Hydrology, 392, 174-187. https://doi.org/10.1016/j.jhydrol.2010.08.006

Pimentel, D., Hepperly, P., Hanson, J., Douds, D., \& Seidel, R. (2011). Environmental, Energetic, and Economic Comparisons of Organic and Conventional Framing Systems. Bio Science, 55(7), 573-580. https://doi.org/ 10.1641/0006-3568(2005)055[0573:EEAECO]2.0.CO;2

Seldon, T. M., \& Song, D. (1994). Environmental quality and development: Is there a Kuznets Curve for air pollution emissions. Journal of Environmental Economics and Management, 27(2), 147-52. https://doi.org/ 10.1006/jeem.1994.1031

Semaan, J., Flichman, G., Scardigno, A., \& Steduto, P. (2007). Analysis of nitrate pollution control policies in the irrigated agriculture of Apulia Region (Southern Italy): A bio-economic modeling approach. Agricultural Systems, 94, 357-367. https://doi.org/10.1016/j.agsy.2006.10.003

Seyed Sharifi, R., Ganbari, P., Khavazi, K., \& Kamari, H. (2016). Study of interaction between nitrogen and biofertilizers on yield, grain growth of wheat and fertilizer use efficiency. Journal of Soil Biology, 4(1), $1-14$.

Sharasbi, S., Emam, Y., Ronaghi, A., \& Pirasteh Anoshe, H. (2016). Effect of drought stress and nitrogen fertilizer on grain yield and nitrogen use efficiency of wheat in Fars province, Iran conditions. Iranian Journal of Crop Science, 17(4), 349-363.

Shober, A. L. (2014). Nitrogen in the Home Landscape. Retrieved from http://edis.ifas.ufl.edu

United Nations Environment Programme. (2014). UNEP year book, emerging issues in our global environment. Retrieved from http://www.epa.gov/nutrientpollution

United Nations of Food and Agriculture Organization. (2011). Fertilizers as Water Pollutants. Natural Resources Management and Environment Department. Retrieved from http://www.fao.org/docrep/w2598e/ w2598e06.htm

Wang, D. J., Liu, Q., Lin, Q., Lin, J. H., \& Sun, R. J. (2004). Optimum Nitrogen Use and Reduced Nitrogen Loss for Production of Rice and Wheat in the Yangtse Delta Region. Environmental Geochemistry and Health, 26(2), 221-227. https://doi.org/10.1023/B:EGAH.0000039584.35434.e0

Zhou, Y., Yang, H., Mosler, H. J., \& Abbaspour, K. C. (2010). Factors affecting farmers' decisions on fertilizer use: A case study for the Chaobai watershed in Northern China. The Journal of Sustainable Development, 4, 80-102. https://doi.org/10.7916/D8C24W3R

Zhu, Z. L., \& Chen, D. L. (2002). Nitrogen fertilizer use in China-Contributions to food production, impacts on the environment and best management strategies. Nutrient Cycling in Agroecosystems, 63, 117-127. https://doi.org/10.1023/A:1021107026067

\section{Copyrights}

Copyright for this article is retained by the author(s), with first publication rights granted to the journal.

This is an open-access article distributed under the terms and conditions of the Creative Commons Attribution license (http://creativecommons.org/licenses/by/4.0/). 